\title{
POSSÍVEL ESTRATÉGIA DE ATIVISMO DE FUNDOS DE PENSÃO NO BRASIL*
}

\author{
Vicente Lima Crisóstomo ${ }^{* *}$
}

\section{Eleuterio Vallelado González ${ }^{* * *}$}

\begin{abstract}
RESUMO $\mathrm{O}$ ativismo de acionistas traduz-se por uma postura ativa destes quando passam a impor suas demandas à direção da empresa. Acionistas individuais e institucionais têm utilizado, em distintos mercados — notadamente nos EUA estratégias de ativismo buscando defender seus interesses. Este trabalho tem o objetivo de apresentar indícios, no mercado brasileiro, que podem ser indicativos de uma estratégia de ativismo adotada pelos fundos de pensão no Brasil. Como resultado, se aponta um crescimento na participação desses fundos no capital votante no período 1995-2002. Além da participação na propriedade, faz-se também uma análise comparativa de índices de desempenho de empresas com forte presença desses investidores institucionais em contraste com as demais.
\end{abstract}

Palavras-chave: ativismo de acionistas; fundos de pensão; propriedade; desempenho

Código JEL: G23, G32

* Artigo recebido em 28 de fevereiro de 2005 e aprovado em 2 de fevereiro de 2006.

** Professor do Departamento de Contabilidade da UFCe, doutorando da Universidad de Valladolid com o apoio do Programa Alban, Programa de Bolsas de Alto Nível da União Européia para a América Latina, n. de identificação E03D23923BR, e-mail: vlc@ufc.br

*** Professor do Departamento de Economia Financiera y contabilidad/Universidad de Valladolid, e-mail: teyo.vallelado@gmail.com 


\section{POSSIBLE ACTIVISM STRATEGY OF PENSION FUNDS IN BRAZIL}

ABSTRACT Shareholder activism can be seen as an active behavior of shareholders when they start to impose their needs to the company direction. In different markets, mainly in USA, individual and institutional shareholders have used activism strategies with the purpose of defending their interests. This work has as main objective showing facts, in the Brazilian market, that may indicative the existence of an activism strategy adopted by the pension funds in Brazil. As result it can be mentioned the growing participation of such funds in the voting capital of companies in the period 1995-2002. Besides that, it is also shown a comparative analysis of some performance indices of companies with and without such strong institutional presence in the voting capital.

Key words: sharehold activism; pension funds; ownership 


\section{INTRODUÇÃO}

O universo no qual está inserida a empresa é, na realidade, um complexo de relações entre diversos atores com interesses distintos. Jensen (2001) faz considerações a respeito dessa diversidade buscando um caminho de união entre eles. Jensen e Meckling (1976), com base na teoria da agência, apresentam um quadro das relações entre os agentes que compõem a empresa e os diversos aspectos relacionados com o contraste entre propriedade e controle, representados pelos proprietários e os diretores. Esses dois agentes são uma amostra do conjunto de agentes que podem ter interação com a empresa visando à satisfação de seus interesses. Exemplos do conjunto de outros elementos são os clientes, o governo, empregados, agentes financeiros e acionistas minoritários, compondo o grande grupo de entes com interesse na empresa conhecido como stakeholders. A importância dos stakeholders com relação à empresa, somada ao tema da responsabilidade social da empresa, cresce a cada dia, como se pode comprovar pelo trabalho de Harrison e Freeman (1999) que apresenta resumidamente seis artigos com pesquisas referentes a este tema nos quais está contida evidência empírica de que as empresas sofrem influência dos stakeholders em algumas de suas práticas. A empresa deve buscar uma forma de atender às demandas dos diversos stakeholders e, ao mesmo tempo, garantir o alcance dos seus objetivos principais de mercado. Os stakeholders, por sua vez, também adotam diferentes estratégias para exigir a satisfação de suas demandas. Os acionistas, especialmente por sua característica de participação na propriedade, têm direitos formais perante a empresa. Apesar disso, nem sempre são respeitados pela direção que, muitas vezes, procede de maneira discricionária gerando problemas de agência (Jensen e Meckling, 1976; Fama e Jensen, 1983).

Para enfrentar tais situações e outras similares, os acionistas costumam adotar diferentes estratégias de acordo com o seu grau de participação na propriedade e o seu interesse em manter-se nela. Tais estratégias podem variar em função da participação na propriedade de modo a gerar mais poder de pressão. Esse conjunto de estratégias de ação tem-se diversificado e aprimorado, dando origem ao chamado ativismo de acionistas (Gillan e Starks, 1998).

O ativismo de acionistas tem sido investigado em mercados desenvolvidos, como comentado por Gillan e Starks (1998), que apresentam evidências favoráveis e desfavoráveis à sua ocorrência. Entretanto, pouca pesquisa há 
sobre isso em mercados em desenvolvimento, como se encontra, por exemplo, em Bainbridge (2000), Choi e Cho (2003) e Sarkar e Sarkar (2000). $\mathrm{O}$ atual amadurecimento do mercado brasileiro já suscita a possibilidade desse tipo de investigação.

Em sua análise, Noe (1997) considera que pesquisas sobre o ativismo de acionistas devem levar em consideração a eficácia dos mecanismos internos de governo corporativo. Dentre suas conclusões, ele comenta que os investidores institucionais podem beneficiar-se com a monitoração da direção da empresa. Entretanto, Black (1998), em sua revisão da evidência existente sobre os investidores institucionais, verifica que os resultados positivos de seu ativismo são reduzidos. Sobre a participação de fundos de pensão na propriedade, Cremers e Nair (2003) encontram uma relação positiva entre esta, juntamente com outros fatores, e o valor da empresa.

O ativismo de investidores institucionais (Noe, 1997; Black, 1998) no mundo, somado à nova realidade do Brasil — caracterizada pelo crescimento do mercado acionário nos anos 1990, pela realidade de um contexto de novos condicionantes apresentados à economia nacional com a abertura comercial e pela redefinição do papel do Estado na economia - e à presença de investidores institucionais como um dos novos agentes articuladores estratégicos no controle de empresas (Siffert, 1998), nos permite propor duas questões de pesquisa para o mercado brasileiro:

(i) Há, na realidade, uma estratégia de ativismo dos fundos de pensão no Brasil de participação na propriedade?

(ii) A participação dos fundos de pensão na propriedade tem algum efeito positivo nos resultados das empresas?

Para responder a estas questões procedeu-se a uma pesquisa em duas direções: avaliar o aumento da participação dos fundos de pensão no período de 1995 a 2002 na propriedade das empresas brasileiras cotizadas e avaliar comparativamente resultados, a partir de diversos índices de desempenho, de empresas com e sem a presença de tais investidores institucionais entre os cinco principais acionistas votantes.

Este trabalho tem como objetivo relatar esta investigação sobre a possibilidade de a participação dos fundos de pensão na propriedade de empresas brasileiras ser um indicativo de uma possível estratégia de ação desse grupo de acionistas ativos e se há algum efeito positivo resultante dessa participação. 
Além desta introdução, este trabalho está composto por 3 seções. A seção 1 apresenta resumidamente a realidade do ativismo de acionistas. A seção 2 relata o trabalho de pesquisa desenvolvido contendo informações sobre os dados e metodologias utilizados seguidas dos resultados obtidos. Por fim, conclusões e considerações finais são apresentadas na seção que encerra o texto.

\section{ATIVISMO DE ACIONISTAS}

\subsection{Conceito de ativismo de acionistas}

Gillan e Starks (1998) afirmam que um importante aspecto do mercado de ações norte-americano nos anos 1990 foi a influência dos acionistas ativos. Confirmando esta opinião, Choi e Cho (2003) dizem que, juntamente com a atenção crescente a questões de governo corporativo, o papel ativo dos acionistas na supervisão e no controle dos diretores está ganhando mais importância. Esse papel ativo dos acionistas pode ser considerado como um conjunto contínuo de reações de acionistas ao desempenho de uma empresa, segundo Gillan e Starks (1998). A definição mais simples e comum de acionista ativo é que ele é aquele investidor que tenta mudar o status quo por meio de pressão. Isso é praticado por acionistas sem controle majoritário, mas que querem influir no processo decisório de modo a ter seus direitos respeitados. De uma certa forma, esse ativismo tem como razão principal a busca de solução de problemas de agência relatados por Jensen e Meckling (1976).

O ativismo tem-se demonstrado em propostas dos acionistas, agrupados ou individualmente, à direção. Segundo Gillan e Starks (1998) e Forjan (1999), tais proposições costumam abordar: compensação de diretores e conselheiros; mudança de diretores e conselheiros; revogação de proteções formais da direção contra possíveis operações de aquisição; mudança na estrutura do conselho de administração; o grau de independência do conselho de administração; cassação do conselho; o grau de participação dos diretores na propriedade; formas de votação em assembléia; recusa a práticas nocivas como greenmail; autorização de voto; e propostas de caráter social.

É comum a existência de empresas alvo eleitas por ativistas. Gillan e Starks (1998) indicam algumas características dessas empresas, tais como pre- 
sença de grandes acionistas investidores institucionais, baixa presença de proprietários na direção e fraca estrutura de governo.

Gillan e Starks (1998) fazem um levantamento histórico do ativismo de acionistas que começa nos anos 1930 nos EUA com uma atividade individual e evolui nos anos 1940 com a ação da SEC (Securities and Exchange Comission), que adota regras sobre o processo de autorização de voto e o envio de propostas a assembléias. Desde então, o movimento tomou força, surgindo associações de acionistas como a ASCS (American Society of Corporate Secretaries), a USA (United Shareholders Association), sucedidas pela IRAA (Investors' Rights Association of America), o IRRC (Investor Responsibility Research Center), o ISS (Institutional Shareholder Services) e, nos anos 1980, a ação marcante de investidores institucionais, notadamente os fundos de pensão.

\subsection{0 ativismo de acionistas por investidores institucionais}

De acordo com Gillan e Starks (1998), o volume de operações no mercado de ações norte-americano por investidores institucionais cresceu de aproximadamente $25 \%$ em 1980 para mais de $50 \%$ das operações em 1994. Tal volume e o conseqüente reflexo na propriedade das empresas os tornaram mais ativos. Segundo os autores, esse ativismo parece ser uma forma de minimizar o problema de free-rider. Em 1985, Jesé Unruh, tesoureiro do estado da Califórnia, modelou o Conselho de Investidores Institucionais como resposta a uma decisão de /greenmailing/ da empresa Texaco de U\$ 137 milhões, para evitar uma operação de aquisição, sem acordo com os acionistas, entre estes, os dois grandes fundos de pensão da Califórnia (CalPERS - /California Public Employees Retirement System/ e CalSTRS - /California State Teachers Retirement System/). O conselho, criado para garantir os direitos dos acionistas, evoluiu e chegou a ser um ponto de referência para ativos acionistas institucionais. Desde então, as estratégias de ativismo dos investidores têm evoluído bastante. Sobre esse ativismo, Bainbridge (2000) reconhece sua importância e os benefícios econômicos representados pela redução de custos de agência. Entretanto adverte também sobre possíveis problemas associados ao risco da defesa de interesses de ativistas em detrimento dos demais acionistas, principalmente em mercados em desenvolvimento. Gillan e Starks (2000) fazem uma pesquisa sobre os resultados de votações e as 
reações do mercado no curto prazo em conseqüência do ativismo nos EUA. Para o período de 1987 a 1994, os autores encontram evidências de que a identidade do autor da proposta está associada ao resultado da votação, sendo os institucionais mais bem-sucedidos - o que demonstra a importância que eles já tinham no mercado. Black (1998) comenta que não há forte evidência de que a participação de investidores institucionais seja um fator benéfico para o desempenho. Smith (1996) aponta o tamanho da empresa e o nível de participação acionária de investidores institucionais como fatores que aumentam a possibilidade de a empresa ser alvo de ativismo.

O Conselho de Investidores Institucionais, inicialmente composto somente por fundos de pensão públicos, no final dos anos 1990, tinha como participantes mais de 100 fundos de pensão públicos e privados que controlavam cerca de U\$ 1 trilhão em ativos financeiros. Esse conselho tinha como objetivo declarado encorajar seus membros, como acionistas principais, a ter um papel ativo na proteção de seus ativos e ajudá-los a incrementar seus retornos sobre investimentos como parte de suas obrigações.

\subsection{Os resultados do ativismo}

Gillan e Starks (1998) comentam as dificuldades para avaliar os efeitos do ativismo, como, por exemplo, ser difícil determinar o sucesso da atividade e se ela gerou conseqüências positivas para a empresa, uma vez que outros fatores também podem ter ocasionado algum efeito positivo; ser também difícil determinar se alguma mudança ocorreu na empresa efetivamente graças à ação dos acionistas ativos; e, também, ser difícil garantir que alguma mudança em função da ação de acionistas será geradora de resultados econômicos positivos para a empresa. Além destas, indica-se também o fato de haver pouca divulgação do ativismo que, muitas vezes, pode ser resolvido por negociação entre as partes, sem muita publicidade do ocorrido.

Apesar das dificuldades, a pesquisa continua. Gillan e Starks (1998) apresentam uma seleção de 23 trabalhos empíricos sobre o ativismo realizados nos EUA de 1987 a 1997. As estratégias de ativismo mais freqüentes estavam baseadas no lançamento de propostas de governo. Não obstante, há também dois estudos de caso de ativismo em empresas específicas e, também, um de ativismo pela manutenção de uma lista de empresas alvo. Os autores comentam os meios utilizados pelas pesquisas para medir os efeitos do ati- 
vismo, que podem ser: as reações do mercado de ações no curto prazo na proximidade da data de divulgação do ativismo; os resultados da votação de propostas de acionistas; o desempenho a longo prazo depois do ativismo; mudanças na empresa alvo do ativismo; e a relação entre investidores institucionais e a empresa.

Smith (1996) encontra evidências de mudanças em empresas somente pela ameaça de ser alvo de ativismo de um acionista institucional e, também, grande número de adoções de propostas oriundas de um fundo de pensão específico. Apesar dos efeitos positivos no valor da empresa, o autor não encontra evidências de mudanças no desempenho operacional.

Forjan (1999) apresenta uma pesquisa realizada nos EUA utilizando dados do IRRC sobre ativismo de acionistas individuais e grupos deles. Ele encontrou retornos negativos significativos no mercado para a divulgação de propostas de acionistas - o que, segundo ele, sugere que, de fato, tais propostas são benéficas para os acionistas só em alguns casos. O autor conclui que o mercado é sensível à relação entre diretores e os ativistas, e que os diretores gastam tempo e recursos para proteger-se das propostas de acionistas, o que é negativo para a empresa. Katz e Owen (2002), numa abordagem teórica, dentre outros resultados, verificam que os acionistas tendem a serem sensíveis a mudanças na participação acionária de ativistas.

Os trabalhos reportados por Gillan e Starks (1998) assim como boa parte da pesquisa sobre o ativismo estão concentrados no mercado norte-americano. Em outros mercados, os estudos são poucos. Há, por exemplo, o trabalho de Bainbridge (2000) que aborda a problemática da concentração de propriedade por fundos de pensão na Slovênia relatando as restrições naquele país para os investidores estrangeiros, como, por exemplo, a necessidade de aprovação do governo para a aquisição de $25 \%$ ou mais de uma empresa privatizada e a proibição de controle total de empresas de alguns setores como telecomunicações e transportes.

$\mathrm{Na}$ Índia, Sarkar e Sarkar (2000) não encontram evidência de ativismo de investidores institucionais. No entanto, encontram que a participação de estrangeiros na propriedade tem efeito positivo no valor das empresas e que a identidade de grandes acionistas interfere na governança corporativa.

Na Coréia, Choi e Cho (2003) comentam que o ativismo de acionistas está concentrado nas ações da ONG (organização não governamental) PSPD 
(People's Solidarity for Participatory Democracy). Os autores comentam o seu objetivo especial de buscar a melhoria do sistema econômico e social na Coréia mais que a maximização de retornos de investimentos, e relatam o histórico de seu ativismo registrado no período de 1997 a 2001. Além disso, declaram que não encontraram melhora significativa no desempenho das empresas, ainda que tenham encontrado algumas melhoras que não podem ser diretamente associadas ao ativismo, o que está em acordo com os resultados obtidos nos EUA. Jang e Kim (2002) comentam sobre a importância da ação da PSPD especificamente em uma empresa, mostrando sua atuação e o poder de influência já conquistado.

No Brasil, Jesus (2004) apresenta um estudo de caso sobre a estratégia de ativismo adotada pela PREVI (Caixa de Previdência dos Funcionários do Banco do Brasil) para participar do controle acionário e ocupar assentos em conselhos de administração e fiscais de empresas - que chegaram a 95 em abril de 2003 cujo fundo detinha pelo menos uma vaga em um desses conselhos.

Os trabalhos sobre Slovenia (Bainbridge, 2000), Coréia (Choi e Cho, 2003), assim como (Gillan e Starks, 2000) e (Smith, 1996) chamam atenção para os investidores institucionais. Gillan e Starks dizem que o ativismo dos investidores institucionais por fundos de pensão começou no ano de 1987, o que significa que é recente. Forjan (1999) considera esse como um dos ativismos de resultados, contrariamente aos individuais. Os resultados de Smith (1996) vão também nesta direção. Estes fatos sugerem a importância de outras pesquisas sobre o ativismo e, especificamente, o ativismo de investidores institucionais e fundos de pensão em outros mercados. A seção seguinte contém exatamente uma pesquisa nesta direção sobre os fundos de pensão no Brasil.

\section{POSSÍVEL ESTRATÉgia de ATIVISMO dOS FUNDOS DE PENSÃO NO BRASIL}

O Brasil talvez tenha peculiaridades comuns a outros países ainda caracterizados pela concentração de propriedade e mercados de capitais em evolução como Coréia (Choi e Cho, 2003), Slovênia (Bainbridge, 2000) e Índia (Sarkar e Sarkar, 2000). Em tais mercados, costuma ser raro o ativismo de 
investidores individuais como encontrado no mercado norte-americano. Entretanto, os investidores institucionais têm apresentado crescente importância para esses mercados.

Sobre a concentração da propriedade no Brasil, dados de Carvalhal-daSilva e Leal (2003) indicam que $72 \%$ do capital votante das empresas está em mãos do principal acionista e $87 \%$ está em poder dos cinco maiores proprietários. Em um mercado como esse, é difícil surgirem investidores individuais ou grupos deles capazes de ter uma atividade mais efetiva. Desta forma, pesquisar o ativismo de acionistas no Brasil ainda é difícil. Acrescente-se o fato de não haver associações de acionistas fortes formalmente constituídas. Além disso, ocorrências dessas atividades, se existem, também não estão ainda devidamente documentadas e publicadas.

Nos anos 1990, pode-se observar uma participação mais efetiva dos investidores institucionais no mercado de ações do país, principalmente a partir do processo de privatização, como relatado por Jesus (2004).

Este trabalho de pesquisa buscou verificar se, efetivamente, é possível considerar a participação no capital votante como uma estratégia de ativismo dos fundos de pensão no Brasil. Isso significaria que, realmente, eles estão adotando um dos objetivos do Conselho de Investidores Institucionais norte-americano (Gillan e Starks, 1998). Além disso, buscou-se também verificar se a presença desses investidores na propriedade influencia o desempenho das empresas.

O fenômeno do ativismo de acionistas no mundo aliado à situação brasileira nos permite propor duas hipóteses de pesquisa:

(i) O número de empresas com participação em fundos de pensão no capital votante entre os cinco principais acionistas cresceu no período de 1995 a 2002, indicando uma possível estratégia de ativismo desses investidores.

(ii) A participação de fundos de pensão como principal acionista nas empresas brasileiras tem influência positiva no desempenho delas.

Para fazer face a essas hipóteses, utilizaram-se a estratégia e as metodologias apresentadas a seguir.

\subsection{Amostra e metodologia}

Os dados para a pesquisa foram obtidos na Bolsa de Valores do Estado de São Paulo (Bovespa) e de Economatica, referentes aos anos de 1995 e 2002. Foram consideradas na pesquisa as empresas que tiveram negociação nos 
respectivos períodos. Assim, a amostra foi composta por 158 empresas em 1995 e 232 em 2002. Utilizou-se o ano de 1995 por ser o ano de início de um período de estabilização monetária a partir do Plano Real e também por já se ter um programa de desestatização em marcha desde alguns anos (Siffert, 1998), e assim buscou-se evitar influências de movimentos do início desse processo.

Para verificar o crescimento na participação utilizou-se o teste qui-quadrado de Pearson, comparando a presença dos fundos de pensão entre os cinco principais acionistas votantes nos anos de 1995 e 2002. Além disso, registrou-se a presença total dos fundos de pensão em cada uma das cinco primeiras posições como acionista majoritário, uma vez que há empresas com mais de um fundo nesse grupo.

Quanto ao desempenho, utilizou-se contraste de médias entre alguns índices das empresas para cada período entre o grupo de empresas sem e o outro com a presença de algum fundo no grupo dos cinco maiores acionistas. Esta abordagem é uma tentativa inicial de investigar se pode haver algum efeito positivo decorrente da presença dos fundos de pensão como acionistas principais, uma vez que há outros fatores que também influem no desempenho das empresas, como comenta Black (1998), além de não haver fortes evidências do efeito positivo dessa participação. Os resultados obtidos estão apresentados na seção seguinte.

\subsection{Resultados obtidos}

\subsubsection{Participação dos fundos de pensão na propriedade}

Com relação à primeira hipótese do crescimento da participação dos fundos de pensão entre os cinco principais acionistas com capital votante no período de 1995 a 2002, algumas considerações podem ser feitas. A mudança no número de empresas que tinham fundos de pensão entre os cinco maiores acionistas em 1995 e 2002 está mostrada na tabela 1. Essa participação está registrada pela presença de pelo menos um fundo de pensão entre os cinco acionistas votantes majoritários. $\mathrm{O}$ resultado $(2=0,593$; $p$-value $=$ $0,441)$ descarta a hipótese estatística de mudança significativa no número de empresas com fundo de pensão nesse grupo de proprietários. Apesar de o crescimento da participação desses investidores não ser estatisticamente significante, pode-se ver que houve um crescimento de 13,9\% em 1995 para $16,8 \%$ em 2002. É interessante destacar o número efetivo de 22 para 39, uma 
vez que isto significa um crescimento de 17 empresas, aproximadamente $77 \%$ de incremento no número de empresas que tinham pelo menos um fundo de pensão entre os cinco maiores acionistas. No mesmo período, o número de empresas sem esta presença decresceu de $86,1 \%$ para $83,2 \%$.

Destaque-se que esses números são referentes a haver ou não fundo de pensão no grupo dos cinco maiores acionistas. Uma informação adicional que merece destaque é o fato de que algumas empresas têm mais de um fundo de pensão entre os cinco principais controladores. Exemplo desta situação é a empresa Perdigão SA, que em 1995 já tinha três fundos de pensão entre os três maiores acionistas com capital votante e em 2002 os três permaneciam, além de outro fundo figurar como quarto maior acionista. Outro exemplo é a empresa Tupy SA, que tinha dois fundos no grupo de cinco principais acionistas em 1995 e passou a ter três em 2002. Comentese ainda que nas duas empresas os fundos já sócios incrementaram suas participações na propriedade no período em estudo. A tabela 2 apresenta, para os dois anos, a freqüência de participação dos fundos de pensão como primeiro, segundo, terceiro, quarto ou quinto maior acionista.

Esses números aprofundam a informação contida na tabela 1 e demonstram que a participação dos fundos como primeiro a quarto acionista cresceu numericamente no período, sendo estatisticamente significante no nível de $1 \%(2=8,732 ; p$-value $=0,03)$ o crescimento da participação de fundos de pensão como quarto acionista em comparação à participação dos outros acionistas, como se pode ver na tabela 3, que considera o universo de empresas que apresentavam um quarto maior acionista em cada ano pesquisado, 74 e 76, respectivamente, em 1995 e 2002.

Tabela 1: Proporção da presença dos fundos de pensão no grupo dos cinco acionistas majoritários em 1995 e 2002

A tabela contém o número de empresas (e percentual em cada ano) sem e com a presença de fundo de pensão como um ou mais de um dos cinco acionistas votantes principais para os anos de 1995 e 2002 que tiveram, respectivamente, 158 e 232 empresas consideradas.

\begin{tabular}{lcc}
\hline \multirow{2}{*}{$\begin{array}{l}\text { Presença ou não de fundo de pensão } \\
\text { entre os cinco principais acionistas }\end{array}$} & \multicolumn{2}{c}{ Anómero de empresas } \\
\hline \multirow{2}{*}{ Sem fundo de pensão } & 1995 & 2002 \\
\hline Com fundo de pensão & 136 & 193 \\
& $(86,1 \%)$ & $(83,2 \%)$ \\
\hline Total & 22 & 39 \\
\hline
\end{tabular}


Tabela 2: Presença de fundo de pensão figurando como $1^{\circ}$ a $5^{\circ}$ maior acionista

A tabela contém o número de ocorrências de fundos de pensão como $1^{\circ}, 2^{\circ}, 3^{\circ}, 4^{\circ}$ ou $5^{\circ}$ acionista em cada ano considerado e o percentual que esse número representa dentro do conjunto de empresas com fundo de pensão presente no grupo dos cinco acionistas majoritários, 22 em 1995 e 39 em 2002, respectivamente (2ª linha da tabela 1)

\begin{tabular}{lcc}
\hline Situação de fundo de pensão & \multicolumn{2}{c}{ Ano } \\
como acionista votante & 1995 & 2002 \\
\hline $1^{\circ}$ acionista & 4 & 6 \\
& $(18,2 \%)$ & $(15,4 \%)$ \\
\hline $2^{\circ}$ acionista & 10 & 19 \\
\hline $3^{\circ}$ acionista & $(45,5 \%)$ & $(48,7 \%)$ \\
\hline $4^{\circ}$ acionista & 12 & 20 \\
\hline $5^{\circ}$ acionista & $(54,5 \%)$ & $(51,3 \%)$ \\
\hline Total & 3 & 15 \\
\hline
\end{tabular}

Tabela 3: Crescimento da participação dos fundos de pensão como $4^{\circ}$ maior acionista

A tabela apresenta o número de empresas que têm fundo de pensão como $4^{\circ}$ maior acionista votante e respectiva proporção dentro do conjunto das empresas que chegam a ter um $4^{\circ}$ maior acionista divulgado pela Bovespa, 74 empresas em 1995 e 76 em 2002, respectivamente

\begin{tabular}{lcc}
\hline \multirow{2}{*}{$\begin{array}{l}\text { Presença ou não de fundo de pensão } \\
\text { como } 4^{\circ} \text { principal acionista }\end{array}$} & \multicolumn{2}{c}{ Número de empresas } \\
\hline & 1995 & 2002 \\
\hline Sem fundo de pensão & 71 & 61 \\
& $(95,9 \%)$ & $(80,3 \%)$ \\
\hline Com fundo de pensão & 3 & 15 \\
\hline Total & $(4,1 \%)$ & $(19,7 \%)$ \\
\hline
\end{tabular}

Em geral, apesar de o crescimento da presença dos fundos de pensão em todo o conjunto dos cinco acionistas principais no período da pesquisa não ser estatisticamente significante, houve um crescimento relativo dessa participação nas empresas brasileiras de 1995 a 2002 que se pode verificar também com a presença de mais de um fundo em cada empresa. Esses números podem ser indicadores de uma estratégia de ação dos fundos de pensão no Brasil caracterizada pela participação mais efetiva na propriedade que pode ter efeitos no controle.

A seguir apresentam-se aspectos relacionados com o desempenho de empresas brasileiras e a participação dos fundos de pensão em sua propriedade. 


\subsubsection{Possível efeito no desempenho das empresas}

O melhor desempenho das empresas é um dos principais objetivos dos acionistas sempre, e, efetivamente, o ativismo de acionistas tem, além de metas pontuais em cada momento, o desempenho no curto e no longo prazos como objetivo principal, conforme comentado na seção 2. Neste sentido, a comparação do desempenho entre grupos de empresas sem e com a participação de um fundo de pensão entre os cinco principais acionistas é uma abordagem inicial para se buscar possíveis diferenças de desempenho que se possam dever a esta presença institucional mais forte na propriedade.

Nesta pesquisa consideraram-se os seguintes índices para cada grupo de empresas em cada um dos dois anos: o $Q$ de Tobin aproximado pelo quociente entre valor de mercado e valor contábil; dividendos por ação; lucro por ação; rentabilidade do ativo; e rentabilidade do patrimônio líquido.

\section{Tabela 4: Comparação de médias de índices de desempenho em 1995}

A tabela contém as médias dos índices considerados para o ano de 1995 para empresas sem fundo de pensão (coluna 2) comparativamente com aquelas nas quais pelo menos 1 fundo figura entre os cinco maiores acionistas (coluna 3). As colunas 4 e 5 apresentam os respectivos valores do estatístico $t$ e $p$-value para cada média comparada

\begin{tabular}{lcccc}
\hline \multirow{2}{*}{ Medida } & \multicolumn{2}{c}{ Média de índices de empresas } & & \\
\cline { 2 - 3 } & $\begin{array}{c}\text { Sem fundo de pensão } \\
\text { (136 empresas) }\end{array}$ & $\begin{array}{c}\text { Com fundo de pensão } \\
\text { (22 empresas) }\end{array}$ & Estatístico $t$ & $p$-value \\
\hline Q de Tobin & 0,5362 & 0,5373 & $-0,0061$ & 0,9952 \\
\hline Dividendo por ação & 0,0742 & 0,0464 & 0,2610 & 0,7945 \\
\hline Lucro por ação & 0,0290 & $-1,9973$ & 2,7054 & $0,0076^{*}$ \\
\hline Rentabilidade do ativo & $-0,0016$ & $-0,0194$ & 0,5294 & 0,5973 \\
\hline Rentabilidade do PL & $-0,3667$ & $-0,2085$ & 0,8920 & 0,3737 \\
\hline
\end{tabular}

* Significativo ao nível 0,01.

Tabela 5: Comparação de médias de índices de desempenho em 2002

A tabela contém as médias dos índices considerados para o ano de 2002 para empresas sem fundo de pensão (coluna 2) comparativamente com aquelas onde pelo menos 1 fundo figura entre os cinco maiores acionistas (coluna 3).

As colunas 4 e 5 apresentam os respectivos valores do estatístico $t$ e $p$-value para cada média comparada

\begin{tabular}{lcccc}
\hline \multirow{2}{*}{ Medida } & \multicolumn{2}{c}{ Média de índices de empresas } & & \\
\cline { 2 - 4 } & $\begin{array}{c}\text { Sem fundo de pensão } \\
(193 \text { empresas })\end{array}$ & $\begin{array}{c}\text { Com fundo de pensão } \\
\text { (39 empresas) }\end{array}$ & Estatístico $t$ & $p$-value \\
\hline Q de Tobin & 0,9297 & 1,1737 & $-0,8312$ & 0,4067 \\
\hline Dividendo por ação & 0,1926 & 1,0431 & $-1,8771$ & $0,0618^{*}$ \\
\hline Lucro por ação & $-0,8212$ & 1,6970 & $-1,5153$ & 0,1310 \\
\hline Rentabilidade do ativo & $-0,5405$ & $-0,0055$ & $-0,7748$ & 0,4393 \\
\hline Rentabilidade do PL & $-0,3247$ & $-0,6483$ & 0,4064 & 0,6849 \\
\hline
\end{tabular}

\footnotetext{
* Significativo ao nível 0,01.
} 
A tabela 4 contém os resultados da comparação das médias no ano de 1995. Naquele ano não houve diferença estatisticamente significativa entre as empresas sem e com fundo de pensão, exceto pelo lucro por ação que foi superior para o grupo sem fundo de pensão ( $p$-value $=0,0076)$. Entretanto, apesar de as diferenças de médias não serem estatisticamente significativas, o Q de Tobin e a rentabilidade do patrimônio líquido são em média superiores para as empresas com a presença dos fundos.

No ano de 2002, como se pode ver na tabela 5, as diferenças entre os índices dos dois grupos de empresas não foram significativas, exceto pela média de dividendos por ação, que foi superior ao nível de 0,1 ( $t=2,7054$; $p$-value $=0,0618$ ) para o grupo de empresas com a presença dos fundos. No entanto, pode-se verificar que as médias dos índices para as empresas com fundo de pensão foram superiores para quatro dos índices analisados.

Com relação a estes indicadores, o fato de não haver diferença estatisticamente significativa para todos os índices impossibilita a afirmação de que a presença de fundo de pensão como acionista principal seja um forte indício de melhor desempenho. Entretanto, um conjunto de indicadores mais favoráveis a um determinado grupo de empresas pode ser um sinal de alguma característica positiva deste conjunto.

Esses resultados estão na mesma direção dos encontrados por Choi e Cho (2003) na Coréia sobre a atividade da PSPD que trabalha incrementando sua participação na propriedade e, apesar de não significativos, foram detectados melhores índices de desempenho das empresas nas quais isso ocorre.

\section{CONCLUSÕES}

$\mathrm{O}$ ativismo de acionistas tem tido um papel importante no conflito de interesses entre propriedade e controle, principalmente nos mercados mais desenvolvidos como EUA (Gillan e Starks, 1998). Desde os primeiros registros de tal ativismo nos anos 1930 até os dias atuais, com destaque para a atuação dos investidores institucionais, entre eles os fundos de pensão, a partir dos anos 1980, o ativismo de acionistas tem sido uma forma legítima de atuação de acionistas que tem ocasionado efeitos mais freqüentemente positivos que negativos para empresas e acionistas. A estratégia dos acionistas tem evoluído com o objetivo de garantir o respeito a seus direitos. 
No Brasil, não é fácil obter dados sobre o ativismo de acionistas. Na realidade, o mercado de capitais brasileiro ainda está em processo de maturação, sendo caracterizado pela ausência de pequenos investidores e a forte concentração da propriedade. Como destaque nesse mercado, pode-se mencionar a presença dos investidores institucionais fundos de pensão, que desde os anos 1990 até agora parecem ter adotado como estratégia de atuação a forte presença na propriedade. Neste sentido, este trabalho apresenta uma pesquisa sobre a evolução da participação desses investidores no capital votante no período 1995-2002. Os resultados mostram que a participação de tais investidores no período em questão cresceu proporcionalmente, ainda que não de forma estatisticamente significativa.

Com relação a um possível efeito positivo da presença dos fundos de pensão entre os cinco acionistas principais, é difícil afirmar, assim como em outros trabalhos, que tal presença seja um fator determinante para a melhora de desempenho. Entretanto, o que se pode apontar é que, efetivamente, para a maioria dos índices de desempenho analisados, os resultados indicaram uma média superior no ano de 2002 para as empresas que apresentaram fundos de pensão entre os cinco principais acionistas, sendo a média significativamente superior para os dividendos por ação. Em 1995, tal superioridade só se observou para dois dos índices considerados.

Apesar de os resultados aqui apresentados não evidenciarem fortemente a adoção de estratégia, por parte dos fundos de pensão, de participação na propriedade, nota-se que há uma presença crescente desses investidores institucionais na propriedade das empresas brasileiras. Isto pode traduzir-se já como uma forma de ativismo capaz de ocasionar outras.

\section{REFERÊNCIAS BIBLIOGRÁFICAS}

BAINBRIDGE, S. M. (2000) "Constraints on shareholder activism in the United States and Slovenia”. SSRN Working Paper Series.

BLACK, B. S. (1998) "Shareholder Activism and Corporate Governance in the United States". In: The New Palgrave Dictionary of Economics and the Law, v. 3, p. 459-465, http://ssrn. com/abstract $=45100$.

CARVALHAL-DA-SILVA, A. E LEAL, R. (2003) “Corporate governance, market valuation and dividend policy in Brazil”. Coppead Working Paper Series n. 390.

CHOI, WOON-YOUL, CHO, S. H. (2003) “Shareholder activism in Korea: an analysis of PSPD's activities”. Pacific-Basin Financial Journal, 11, p. 349-363. 
CREMERS, K. J. M., NAIR, V. B. (2003) “Governance mechanisms and equity prices” (August). Yale ICF Working Paper n. 03-15; NYU, Ctr for Law and Business Research Paper n. 03-09; AFA 2004, San Diego Meetings, http://ssrn.com/abstract=412140.

FAMA, E. F., JENSEN, M. C. (1983) “Agency problems and residual claims”. Jornal of Law and Economics Foundations of Organization Strategy, chapter 6, Harvard University Press.

FORJAN, J. M. (1999) “The wealth effects of shareholder-sponsored proposals”. Review of Financial Economics, 8, p. 61-72.

GILLAN, S. L., STARKS, L. T. (1998) "A survey on shareholder activism: motivation and empirical evidence”. Contemporary Finance Digest, v. 2, n. 3, p. 10-34, Autumn.

- - $-(2000)$ "Corporate governance proposals and shareholder activism: the role of institutional investors". Journal of Financial Economics, 57, p. 275-305.

HARRISON, J. S., FREEMAN, R. E. (1999) "Stakeholder, social responsibility, and performance: empirical evidence and theoretical perspectives". Academy of Management Journal, v. 42, n. 5.

JANG, H., KIM, J. (2002) "Nascent stages of corporate governance in an emerging market: regulatory change, shareholder activism and Samsung Electronics". Corporate Governance: An International Review, v. 10, p. 94-105, http://ssrn.com/abstract=312106.

JENSEN, M. (2001) "Value maximization, stakeholder theory, and the corporate objective function". Journal of Applied Corporate Finance, v. 14, n. 3, Fall (Social Science Research Network Electronic Paper Collection at: http://papers.ssrn.com/).

JENSEN, M., MECKLING, William H. (1976) “Theory of the Firm: Managerial Behavior, Agency Cost and Ownership Structure”. Journal of Financial Economics, October/1976.

JESUS, R. M. R. (2004). “Governança corporativa: a formação de mecanismos por investidores institucionais, o caso PREVI”. Dissertação de mestrado. Rio de Janeiro: Fundação Getúlio Vargas (Disponível em: www.ibgc.org.br/ibConteudo.asp?IDp=332\&IDArea=1118).

KATZ, B. G., OWEN, J. (2002) “The emergence of concentrated ownership and the rebalancing of portfolios due to shareholder activism in a financial market equilibrium” (October). EFMA 2002 London Meetings, http://ssrn.com/abstract=314379.

NOE, T. H. (1997) "Institutional investor activism and financial market structure" (September). http://ssrn.com/abstract=36569.

SARKAR, J., SARKAR, S. (2000) "Large shareholder activism in corporate governance in developing countries: evidence from India”. International Review of Finance, v. 1, n. 3, September.

SIFFERT FILHO, N. (1998) “Governança corporativa: padrões internacionais e evidências empíricas no Brasil nos anos 90”. Revista BNDES, n. 9, junho.

SMITH, M. P. (1996) "Shareholder activism by institutional investors: evidence from CalPERS". Journal of Finance, v. 51, n. 1, March. 